\section{Welcome to America}

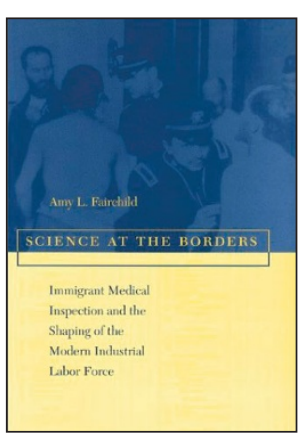

\section{Science at the Borders: Immigrant Medical Inspection and the Shaping of the Modern Industrial Labor Force}

Amy L Fairchild

The Johns Hopkins University Press, 2003 408 pp. hardcover, $\$ 48.00$

ISBN 0-80187-080-1

\section{Reviewed by Antonio Ugalde}

Every period of history is characterized by socio-cultural traits that leave a distinctive imprint in the way humans approach reality and behave. The arts, our definition of morality, and the social construction of human relations are profoundly influenced by these characteristics. Science is not an exception. Fairchild's Science at the Borders is a scholarly effort to reconstruct the multiple purposes of medical inspections of immigrants between 1892 and 1930, when over 25 million people arrived at the US borders. The unique contribution of this monograph is the painstaking effort the author has made to set the medical inspections within their historical context. In doing this, Fairchild goes beyond an account of the role given to medical inspections and the understanding of medicine as a science held by the political leadership, the Immigration Service and the US Public Health Service (PHS). She presents, in addition, the links between the inspections and the 'scientific' principles of industrial management in vogue in those days. This approach allows a critical examination of historical materials, and arrives at provocative conclusions that perhaps will not sway all readers. Nevertheless, it is vastly more valuable than a historical description of facts and events.

An overt objective of the medical examinations was to exclude immigrants who posed a threat to public health because of their "dangerous contagious diseases," or to the economyas a result of conditions such as idiocy, insanity and feeble-mindedness. It was mandatory that all those identified with such conditions be excluded. The PHS had a second classification of conditions that could prevent immigrants from earning a living. Among them we find a diverse collection of hernias, vision problems, poor physique, deformities, nervous affections, pregnancy and anemia, which gave officers a relatively high degree of discretionary power.

Fairchild documents that a very small fraction of immigrants were returned home-of the 25 million immigrants, only half a million were excluded for diseases and defects. This is not surprising, because migration studies have shown that migration is very selective. The young, the healthiest and the most motivated tend to migrate. International migration-even more so in those days, when the decision often implied a one-

Antonio Ugalde is an Emeritus Professor in the Department of Sociology, University of Texas, Austin, Texas 78712-1088, USA.

e-mail: augalde@mail.la.utexas.edu way trip — is a challenging experience, made after careful consideration and generally with good knowledge of what lies ahead. It is therefore unlikely that persons afflicted with some serious and incapacitating disease would migrate. As the reader is told, it was not uncommon that those who feared that they would not pass the health inspection traveled in second instead of third class, as it was known that such passengers were treated with more deference by medical inspectors who assumed that wealthier immigrants enjoyed better health.

According to Fairchild there was another subtle, unwritten objective behind the medical inspections; namely, to transform the future industrial employee, as he or she entered the US, into an obedient and efficient worker. Industrial managers needed migrants who would adjust easily to the controlled environment and monotonous tasks that Frederick W. Taylor, one of the founders of scientific management, had established as the basic principles of this school. The purpose of scientific management was to maximize the productivity of labor by carefully selecting and training workers to carry out repetitive and mechanical motions.

Medical inspections were also meant to inculcate modern American values into the incoming foreign labor force. Fairchild provides a wealth of information to confirm her hypothesis, documenting the asymmetry of power between the uniformed health inspectors and the immigrant, the discretionary power of the bureaucracy, and the dehumanizing organization at stations such as Ellis Island. The long lines, cattle pen-type gates and wire fences aimed at processing as many as possible in the shortest amount of time were a prelude to life in the factories organized under Taylor's principles. Similarly, the cameras installed at Ellis Island and at the factories had the same purpose: to control.

These and other arguments offered by the author have not convinced me that the PHS could hope to socialize immigrants into their new role as industrial workers and indoctrinate them in the values of the receiving society. The array of information presented is impressive, and very useful in understanding the anguish, embarrassment and humiliation caused by the inspections. In too many instances, there was also a lack of sensitivity-for example, when some immigrants were asked to undress in front of others. Without any doubt, immigrants feared the inspections and interrogations by Immigration Service personnel. The PHS and Immigration Service had to process hundreds of thousands of immigrants every year with limited personnel and equipment, and this demand required 'production methods' similar to those used by scientific management. But all that does not imply that the PHS had an unwritten goal of preparing the labor force for its new industrial tasks. The main argument against the thesis is that inculcation of values, acculturation and socialization could not be accomplished in the brief encountersusually about 40 seconds - that the immigrants had with the medical inspectors. Immigrants may have used the terms of total institutions (prisons, cages and guards) to describe their encounters, but what clearly was a process cannot be understood as an institution.

In spite of this limitation, the study makes a solid contribution to our understanding of how easy it is for administrators and political leaders to manipulate science to support their policies. As I was reading the manuscript, I realized time and again how, in essence, much remains unchanged-including the discretionary power of the Immigration and Naturalization Service and the mistreatment of many migrants. 